\title{
Delirium in children - new research directions
}

\author{
Aleksandra Góźdź \\ Department of Clinical Pharmacy and Biopharmacy \\ Poznan University of Medical Sciences, Poznan, Poland \\ Corresponding author: amgozdz@gmail.com

\section{Agnieszka Bienert} \\ Department of Clinical Pharmacy and Biopharmacy, \\ Poznan University of Medical Sciences, Poznan, Poland \\ (iD) https://orcid.org/0000-0001-7272-5738 \\ Alicja Bartkowska-Śniatkowska \\ Department of Pediatric Anesthesiology and Intensive Therapy, \\ Poznań University of Medical Sciences, Poznań, Poland \\ (iD) https://orcid.org/0000-0003-4950-2346 \\ Justyna Alicja Ber \\ Department of Clinical Pharmacy and Biopharmacy, \\ Poznan University of Medical Sciences. Poznan, Poland \\ (iD) https://orcid.org/0000-0003-2270-4386

\section{Erwin Ista} \\ Pediatric Intensive Care Unit, Department of \\ Paediatric Surgery, Erasmus Medical Center - \\ Sophia Children's Hospital, The Netherlands \\ Nursing Science, Department of Internal Medicine, \\ Erasmus Medical Center, Rotterdam, The Netherlands \\ (iD) https://orcid.org/0000-0003-1257-3108
}

DOI: https://doi.org/10.20883/medical.e478

Keywords: delirium, pediatric delirium, children, biomarkers, PK/PD modeling

Published: 2021-02-24

How to Cite: Góźdź A, Bienert A, Bartkowska-Śniatkowska A, Ber JA, Ista E. Delirium in children - new research directions. JMS [Internet]. 2021 Feb 24;90(1):e478. doi:10.20883/ medical.e478

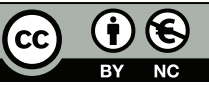

(c) 2021 by the author(s). This is an open access article distributed under the terms and conditions of the Creative Commons Attribution (CC BY-NC) licencse. Published by Poznan University of Medical Sciences

\section{ABSTRACT}

One of the problems associated with a patient's stay in the hospital and the procedures they undergo is delirium, the occurrence of which is associated with numerous complications, longer stay in the ward, higher risk of death and increased healthcare costs. Scientists are continuing to search for effective methods to minimise the risk of its occurrence, as well as to develop effective therapeutic procedures. One such area of the research is the identification of delirium biomarkers, which would allow further PK/PD (pharmacokinetic/pharmacodynamic) modelling. This article focuses on the emergence delirium, which occurs in patients recovering from general anaesthesia.

\section{Definition and risk factors}

Delirium is an acute and rapidly changing disorder of consciousness characterised by a decrease in the ability to focus, maintain or switch attention, accompanied by disorders of cognitive functions (memory deficit, disorientation, language disorders, hallucinations) and perception, which can be diagnosed based on medical history, clinical symptoms, physical examination or laboratory tests. According to the International Classification of Diseases ICD-10, delirium also includes emotional, psychomotor, and sleep-wake cycle disorders [1,2]. Delirium can occur in any setting, but is more common in a hospital setting, mainly in Intensive Care Units (ICU), due to associated clinical deterioration and/or pharmacological agents, such as benzodiazepines, opioids or anticholinergics, which may cause or exacerbate delirium [3-5]. Additionally, a hospital stay can 
contribute to an increased risk of delirium due to exposure to stress, noise, excessive stimulation and the resulting disturbances of sleep and wake rhythm, diagnostic procedures, pain and fear related to a stay in the ward [6-12]. Injury, sepsis, any kind of shock, heart failure and respiratory failure have been associated with tissue hypoperfusion and development of inflammation, which may contribute to delirium $[9,13]$.

\section{Postoperative delirium (POD)}

One form of delirium is postoperative delirium (POD), which can occur in patients who have undergone general anaesthesia for surgery, most often within three days of surgery. The development of POD is associated with a higher risk of death, a longer stay in the ICU and hospital, as well as cognitive impairment and the development of long-term psychiatric disorders, including symptoms of post-traumatic stress disorder [14-18].

\section{Delirium in children}

Children are particularly vulnerable to the occurrence of delirium, due to the dynamic development of their central nervous system, which may be disturbed under the influence of anaesthesia, and the consequences of this process may affect its further functioning. This is important because delirium can affect memory disorders in children, thus learning and intellectual development, even leading to sleep disorders, anxiety, and depression. Children's delirium significantly contributes to the increase in morbidity, mortality, and the costs of hospital care for sick children and adolescents. The current knowledge regarding the occurrence of this phenomenon in children is based mainly on extrapolation of the literature describing delirium in adults and on a few studies conducted in paediatric patients. Therefore, studies to assess the long-term impact of delirium on the development of children are necessary. Despite numerous evidence of a negative impact of delirium in paediatric patients, there are no standardised preventive, diagnostic and therapeutic measures [19]. Developing such rules could reduce the incidence of delirium among children, the length of their hospital stay and the associated costs; inva- sive interventions, such as prolonged mechanical ventilation or prolonged sedation, would be less necessary; ultimately improving the quality of life and the patient's condition [20].

Delirium in newborns and infants is especially difficult to diagnose due to communication limitations. In those age groups, symptoms of delirium include non-purposefulness, difficulty in engaging, agitation, restlessness and difficulty in calming the child [21-23]. Preschool children are most likely to develop delirium, which may be caused by their constant need for stimulation, the lack of which is due to immobilisation during the ICU stay and their increased sensitivity to disturbances in the sleep-wake rhythm [24]. Symptoms of delirium in schoolchildren and adolescents are easier to observe and are similar to those in adult patients [25].

Scales used to assess delirium in children include The Paediatric Anaesthesia Emergence Delirium (PAED) scale, which is used in children $>2$ yrs of age [26] and Cornell Assessment of Paediatric Delirium [27], a rapid observational screening tool to assess delirium in infants. The Cravero and Watcha scales are based on the assessment of levels of consciousness or arousal [28,29].

\section{The importance of delirium pre- vention and current treatment}

The importance of delirium for healthcare systems around the world is emphasised by LaHue et al. in relation to the COVID-19 pandemic caused by the SARS-CoV-2 coronavirus. The authors argue that in the face of a pandemic, there is a need to focus even more on preventing the occurrence of delirium, which is associated with an increased length of stay in the intensive care unit. They suggest that doubling the existing protocols for the prevention and management of delirium could significantly reduce the shortage of hospital beds and ventilators, essential in the fight against COVID-19 [30].

\section{Prevention}

To minimise the incidence of side effects of premedication drugs such as benzodiazepines, including the increased risk of delirium, non- 
pharmacological methods of reducing preoperative anxiety are being sought. West et al. examined 59 children aged 3 to 10 years without coexisting anxiety disorders undergoing elective surgery. Some children were prepared for treatments according to standard procedures that included the use of a local anaesthetic prior to insertion of the needle, a brief consultation with an anesthesiologist and surgeon, and possible administration of anxiolytic drugs. For other children, in addition to the activities covered by standard procedures, "Child life preparation" was used, which consisted of role-playing with dolls and medical equipment, presenting children books and pictures showing activities related to the operating room as well as teaching them to cope with stress and finally translating planned activities according to the patient's age. The study showed a positive effect of additional preoperative activities in reducing the anxiety associated with the procedures by 13.8 points compared to the control group [31]. Another method of reducing preoperative stress in children was investigated by Dwairej et al., who used a combination of gradual accustoming children to the mask used to induce anaesthesia and distracting the child with video games, showing that such methods reduced anxiety during induction of anaesthesia compared to the control group [32].

\section{Treatment}

For the treatment of delirium, neuroleptic and antipsychotic drugs such as haloperidol, olanzapine, quetiapine or risperidone are used [33-36]. POD usually does not require the administration of drugs because it is short-lived, only nonpharmacological methods are used. Delirium in ICU patients lasts longer and very often requires medication, with haloperidol currently recognised as the gold standard delirium treatment. One of the other medicines used to prevent delirium in children is dexmedetomidine, a selective a2-adrenergic agonist in certain parts of the brain, which has a sympathetic, anaesthetic, anxiolytic, sedative and analgesic effect. Studies show that in ICU patients after surgery, dexmedetomidine reduces the need for midazolam, propofol and opioids both on an emergency basis and during sedation. The incidence of delirium measured on the CAM-ICU (Confusion Assessment Method for the ICU) scale after administration of dexmedetomidine was lower compared to midazolam. However, there is a need for further studies on the use of this drug, as there are no unambiguous data on the time of administration and optimal doses in the prevention of delirium [37].

\section{Biomarkers}

To evaluate the risk of developing postoperative delirium, the effectiveness of treatment and disease prognosis, it is necessary to select specific pharmacodynamic and disease progression biomarkers, which requires research and verifying which of them correlate well with the disease and treatment effectiveness. The most frequently mentioned in the context of delirium are: CRP (C-reactive protein), IL-6 (interleukin 6), IL-10, IL-8, PLR (platelet-to-lymphocyte ratio), PWR (platelet-to-white blood cell ratio), NLR (neutrophil-tolymphocyte ratio), BUN/Cre (blood urea nitrogen / creatinine ratio), TNF-a (tumour necrosis factor a), as well as blood cortisol levels [37-49]. Some of the mentioned biomarkers, such as IL-6 and TNF-a, are also typical for the inflammatory response in the postoperative period, therefore it is necessary to specify the biomarkers most specific to delirium [50]. Genetic biomarkers such as the presence of the Apo-E4 alleles seem to be more exact [51].

\section{Mathematical modelling}

Dynamically developing mathematical modelling in medical sciences and population-based approach to data analysis is becoming more widely recommended for determining optimal pharmacotherapy protocols, especially in infants and children [52]. In July 2019, the FDA (Food and Drug Administration) published a new document on the significance and indications for population PK modelling in the pharmaceutical industry and clinical trials [53]. Modern mathematical modelling is not only used in the PK/PD drug analysis, but also in creating disease progression models and evaluating the influence of drugs on the course of disease [54]. 
Acknowledgements

\section{Conflict of interest statement}

The authors declare no conflict of interest.

\section{Funding sources}

There are no sources of funding to declare.

\section{References}

1. Appendix I, DSM-IV and scales for measuring delirium. National Clinical Guideline Centre (UK). Delirium: Diagnosis, Prevention and Management. https:// www.ncbi.nlm.nih.gov/books/NBK65545

2. Whitlock E, Vannucci A, Avidan M. Postoperative delirium. Minerva Anestesiol. 2011;77(4):448-56. PMID 21483389

3. Silver GH, Kearney JA, Bora S, De Souza C, Giles L, Hrycko S, Jenkins W, Malas N, Namerow L, OrtizAguayo R, Russell R, Pao M, Plioplys S, Brahmbhatt K, . A Clinical Pathway to Standardize Care of Children With Delirium in Pediatric Inpatient Settings. Hospital Pediatrics. 2019 Oct 29;9(11):909-916. https://doi. org/10.1542/hpeds.2019-0115

4. Nellis ME, Goel R, Feinstein S, Shahbaz S, Kaur S, Traube C. Association Between Transfusion of RBCs and Subsequent Development of Delirium in Critically III Children*. Pediatric Critical Care Medicine. 2018 Oct;19(10):925-929. https://doi.org/10.1097/ pcc. 0000000000001675

5. Meyburg J, Dill M, Traube C, Silver G, von Haken R. Patterns of Postoperative Delirium in Children*. Pediatric Critical Care Medicine. 2017 Feb;18(2):128-133. https://doi.org/10.1097/pcc.0000000000000993

6. Kawai Y, Weatherhead JR, Traube C, Owens TA, Shaw BE, Fraser EJ, Scott AM, Wojczynski MR, Slaman KL, Cassidy PM, Baker LA, Shellhaas RA, Dahmer MK, Shever LL, Malas NM, Niedner MF. Quality Improvement Initiative to Reduce Pediatric Intensive Care Unit Noise Pollution With the Use of a Pediatric Delirium Bundle. Journal of Intensive Care Medicine. 2017 Sep 1;34(5):383-390. https://doi. org/10.1177/0885066617728030

7. Kain ZN. Preoperative Anxiety in Children. Archives of Pediatrics \& Adolescent Medicine. 1996 Dec 1;150(12):1238. https://doi.org/10.1001/ archpedi.1996.02170370016002

8. Gunther ML, Morandi A, Ely EW. Pathophysiology of Delirium in the Intensive Care Unit. Critical Care Clinics. 2008 Jan;24(1):45-65. https://doi.org/10.1016/j. ccc. 2007.10 .002

9. Maldonado JR. Delirium in the Acute Care Setting: Characteristics, Diagnosis and Treatment. Critical Care Clinics. 2008 Oct;24(4):657-722. https://doi. org/10.1016/j.ccc.2008.05.008

10. Gaudreau J, Gagnon P, Roy M, Harel F, Tremblay A. Association Between Psychoactive Medications and Delirium in Hospitalized Patients: A Critical Review. Psychosomatics. 2005 Jul;46(4):302-316. https:// doi.org/10.1176/appi.psy.46.4.302

11. Han L, McCusker J, Cole M, Abrahamowicz M, Primeau F, Élie M. Use of Medications With Anticholinergic
Effect Predicts Clinical Severity of Delirium Symptoms in Older Medical Inpatients. Archives of Internal Medicine. 2001 Apr 23;161(8):1099. https://doi. org/10.1001/archinte.168.1099

12. Gabor JY, Cooper AB, Crombach SA, Lee B, Kadikar $\mathrm{N}$, Bettger HE, Hanly PJ. Contribution of the Intensive Care Unit Environment to Sleep Disruption in Mechanically Ventilated Patients and Healthy Subjects. American Journal of Respiratory and Critical Care Medicine. 2003 Mar;167(5):708-715. https://doi. org/10.1164/rccm.2201090

13. Engel GL, Romano J. Delirium, A Syndrome of Cerebral Insufficiency. The Journal of Neuropsychiatry and Clinical Neurosciences. 2004 Nov;16(4):526-538. https://doi.org/10.1176/jnp.16.4.526

14. Stollings JL, Thompson JL, Ferrell BA, Scheinin M, Wilkinson GR, Hughes CG, Shintani AK, Ely EW, Girard TD, Pandharipande PP, Patel MB. Sedative Plasma Concentrations and Delirium Risk in Critical Illness. Annals of Pharmacotherapy. 2018 Jan 24;52(6):513521. https://doi.org/10.1177/1060028017753480

15. Pandharipande $P$, Girard T, Jackson J, Morandi A, Thompson J, Pun B, Brummel N, Hughes C, Vasilevskis E, Shintani A, Moons K, Geevarghese S, Canonico A, Hopkins R, Bernard G, Dittus R, Ely E. Long-Term Cognitive Impairment after Critical Illness. New England Journal of Medicine. 2013 Oct 3;369(14):13061316. https://doi.org/10.1056/nejmoa1301372

16. Bolton C, Thilges S, Lane C, Lowe J, Mumby P. Posttraumatic Stress Disorder Following Acute Delirium. Journal of Clinical Psychology in Medical Settings. 2019 Dec 10;. https://doi.org/10.1007/s10880-01909689-1

17. Colville G, Kerry S, Pierce C. Children's Factual and Delusional Memories of Intensive Care. American Journal of Respiratory and Critical Care Medicine. 2008 May;177(9):976-982. https://doi.org/10.1164/ rccm.200706-857oc

18. Marcantonio ER, Rudolph JL, Culley D, Crosby G, Alsop D, Inouye SK. Review Article: Serum Biomarkers for Delirium. The Journals of Gerontology Series A: Biological Sciences and Medical Sciences. 2006 Dec 1;61(12):1281-1286. https://doi.org/10.1093/ gerona/612.1281

19. Trogrlić Z, Ista E, Ponssen HH, Schoonderbeek JF, Schreiner F, Verbrugge SJ, Dijkstra A, Bakker J, van der Jagt $M$. Attitudes, knowledge and practices concerning delirium: a survey among intensive care unit professionals. Nursing in Critical Care. 2016 Mar 20;22(3):133-140. https://doi.org/10.1111/nicc.12239

20. Rotter T, Kinsman L, James EL, Machotta A, Gothe H, Willis J, Snow P, Kugler J. Clinical pathways: effects on professional practice, patient outcomes, length of stay and hospital costs. . Cochrane Database of Systematic Reviews. 2010 Mar 17; https://doi. org/10.1002/14651858.cd006632.pub2

21. Brahmbhatt K, Whitgob E. Diagnosis and Management of Delirium in Critically III Infants: Case Report and Review. Pediatrics. 2016 Feb 2;137(3):e20151940. https://doi.org/10.1542/peds.2015-1940

22. Schieveld JNM, Leroy PLJM, van Os J, Nicolai J, Vos GD, Leentjens AFG. Pediatric delirium in critical ill- 
ness: phenomenology, clinical correlates and treatment response in 40 cases in the pediatric intensive care unit. Intensive Care Medicine. $2007 \mathrm{Apr}$ 25;33(6):1033-1040. https://doi.org/10.1007/s00134007-0637-8

23. Mason K. Paediatric emergence delirium: a comprehensive review and interpretation of the literature. British Journal of Anaesthesia. 2017 Mar;118(3):335343. https://doi.org/10.1093/bja/aew477

24. Silver G, Traube C, Gerber LM, Sun X, Kearney J, Patel A, Greenwald B. Pediatric Delirium and Associated Risk Factors. Pediatric Critical Care Medicine. 2015 May;16(4):303-309. https://doi.org/10.1097/ pcc. 0000000000000356

25. Hatherill S, Flisher AJ. Delirium in children and adolescents: A systematic review of the literature. Journal of Psychosomatic Research. 2010 Apr;68(4):337-344. https://doi.org/10.1016/j.jpsychores.2009.10.011

26. Mason K. Paediatric emergence delirium: a comprehensive review and interpretation of the literature. British Journal of Anaesthesia. 2017 Mar;118(3):335343. https://doi.org/10.1093/bja/aew477

27. Traube C, Silver G, Kearney J, Patel A, Atkinson TM, Yoon MJ, Halpert S, Augenstein J, Sickles LE, Li C, Greenwald B. Cornell Assessment of Pediatric Delirium. Critical Care Medicine. 2014 Mar;42(3):656-663. https://doi.org/10.1097/ccm.0b013e3182a66b76

28. Menser C, Smith H. Emergence Agitation and Delirium: Considerations for Epidemiology and Routine Monitoring in Pediatric Patients. Local and Regional Anesthesia. 2020 Jul;13:73-83. https://doi. org/10.2147//ra.s181459

29. Bajwa SA, Costi D, Cyna AM. A comparison of emergence delirium scales following general anesthesia in children. Pediatric Anesthesia. 2010 May 20;20(8):704-711. https://doi.org/10.1111/j.14609592.2010.03328.x

30. LaHue SC, James TC, Newman JC, Esmaili AM, Ormseth $\mathrm{CH}$, Ely EW. Collaborative Delirium Prevention in the Age of COVID 19. Journal of the American Geriatrics Society. 2020 May;68(5):947-949. https://doi. org/10.1111/jgs. 16480

31. West N, Christopher N, Stratton K, Görges M, Brown Z. Reducing preoperative anxiety with Child Life preparation prior to intravenous induction of anesthesia: A randomized controlled trial. Pediatric Anesthesia. 2020 Jan 8;30(2):168-180. https://doi.org/10.1111/ pan.13802

32. Dwairej DA, Obeidat HM, Aloweidi AS. Video game distraction and anesthesia mask practice reduces children's preoperative anxiety: A randomized clinical trial. Journal for Specialists in Pediatric Nursing 2019 Oct;25(1). https://doi.org/10.1111/jspn.12272

33. Faria RDSB, Moreno RP. Delirium in intensive care: an under-diagnosed reality. Revista Brasileira de Terapia Intensiva. 2013;25(2):137-147. https://doi. org/10.5935/0103-507x.20130025

34. Joyce C, Witcher R, Herrup E, Kaur S, Mendez-Rico E, Silver G, Greenwald BM, Traube C. Evaluation of the Safety of Quetiapine in Treating Delirium in Critically III Children: A Retrospective Review. Journal of Child and Adolescent Psychopharmacology.
2015 Nov;25(9):666-670. https://doi.org/10.1089/ cap. 2015.0093

35. Cunningham ME, Vogel AM. Analgesia, sedation, and delirium in pediatric surgical critical care. Seminars in Pediatric Surgery. 2019 Feb;28(1):33-42. https:// doi.org/10.1053/j.sempedsurg. 2019.0006

36. Schieveld JNM, Leroy PLJM, van Os J, Nicolai J, Vos GD, Leentjens AFG. Pediatric delirium in critical illness: phenomenology, clinical correlates and treatment response in 40 cases in the pediatric intensive care unit. Intensive Care Medicine. $2007 \mathrm{Apr}$ 25;33(6):1033-1040. https://doi.org/10.1007/s00134007-0637-8

37. Population Pharmacokinetics. Guidance for Industry. https://www.fda.gov/media/128793/download

38. Toft K, Tontsch J, Abdelhamid S, Steiner L, Siegemund $M$, Hollinger A. Serum biomarkers of delirium in the elderly: a narrative review. Annals of Intensive Care. 2019 Jul 1;9(1). https://doi.org/10.1186/s13613019-0548-1

39. Liu X, Yu Y, Zhu S. Inflammatory markers in postoperative delirium (POD) and cognitive dysfunction (POCD): A meta-analysis of observational studies. Ma D. PLOS ONE. 2018 Apr 11;13(4):e0195659. https://doi.org/10.1371/journal.pone.0195659

40. Kazmierski J, Banys A, Latek J, Bourke J, Jaszewski R. Cortisol levels and neuropsychiatric diagnosis as markers of postoperative delirium: a prospective cohort study. Critical Care. 2013;17(2):R38. https:// doi.org/10.1186/cc12548

41. Khan BA, Zawahiri M, Campbell NL, Boustani MA. Biomarkers for Delirium-A Review. Journal of the American Geriatrics Society. 2011 Nov;59:S256-S261. https://doi.org/10.1111/j.1532-5415.20103702.x

42. Marcantonio ER, Rudolph JL, Culley D, Crosby G, Alsop D, Inouye SK. Review Article: Serum Biomarkers for Delirium. The Journals of Gerontology Series A: Biological Sciences and Medical Sciences. 2006 Dec 1;61(12):1281-1286. https://doi.org/10.1093/ gerona/612.1281

43. Kotfis K, Bott-Olejnik M, Szylińska A, Rotter I. Could Neutrophil-to-Lymphocyte Ratio (NLR) Serve as a Potential Marker for Delirium Prediction in Patients with Acute Ischemic Stroke? A Prospective Observational Study. Journal of Clinical Medicine. $2019 \mathrm{Jul}$ 22;8(7):1075. https://doi.org/10.3390/jcm8071075

44. Amgarth-Duff I, Hosie A, Caplan G, Agar M. A systematic review of the overlap of fluid biomarkers in delirium and advanced cancer-related syndromes. BMC Psychiatry. 2020 Apr 22;20(1). https://doi. org/10.1186/s12888-020-02584-2

45. Kozak HH, Uğuz F, Kılınç İ, Uca AU, Serhat Tokgöz O, Akpınar Z, Özer N. Delirium in patients with acute ischemic stroke admitted to the non-intensive stroke unit: Incidence and association between clinical features and inflammatory markers. Neurologia i Neurochirurgia Polska. 2017 Jan;51(1):38-44. https://doi. org/10.1016/j.pjnns.2016.10.004

46. Vasunilashorn SM, Dillon ST, Inouye SK, Ngo LH, Fong TG, Jones RN, Travison TG, Schmitt EM, Alsop DC, Freedman SD, Arnold SE, Metzger ED, Libermann TA, Marcantonio ER. High C-Reactive Protein Predicts 
Delirium Incidence, Duration, and Feature Severity After Major Noncardiac Surgery. Journal of the American Geriatrics Society. 2017 May 26;65(8):e109-e116. https://doi.org/10.1111/jgs.14913

47. Dillon ST, Vasunilashorn SM, Ngo L, Otu HH, Inouye SK, Jones RN, Alsop DC, Kuchel GA, Metzger ED, Arnold SE, Marcantonio ER, Libermann TA. Higher C-Reactive Protein Levels Predict Postoperative Delirium in Older Patients Undergoing Major Elective Surgery: A Longitudinal Nested Case-Control Study. Biological Psychiatry. 2017 Jan;81(2):145-153. https://doi.org/10.1016/j.biopsych.2016.03.2098

48. Stasevic-Karlicic I, Stasevic M, Jankovic S, DjukicDejanovic S, Milovanovic S. Markers of inflammation as risk predictors of lethal outcome in patients diagnosed with delirium. Vojnosanitetski pregled. 2016;73(9):838-843. https://doi.org/10.2298/ vsp141212012s

49. Neerland BE, Hall RJ, Seljeflot I, Frihagen F, MacLullich AMJ, Raeder J, Wyller TB, Watne LO. Associations Between Delirium and Preoperative Cerebrospinal Fluid C-Reactive Protein, Interleukin-6, and Inter- leukin-6 Receptor in Individuals with Acute Hip Fracture. Journal of the American Geriatrics Society. 2016 Jun 24;64(7):1456-1463. https://doi.org/10.1111/ jgs. 14238

50. Dąbrowska AM, Słotwiński R. The immune response to surgery and infection. Central European Journal of Immunology. 2014;4:532-537. https://doi. org/10.5114/ceji.2014.47741

51. Khan BA, Zawahiri M, Campbell NL, Boustani MA. Biomarkers for Delirium-A Review. Journal of the American Geriatrics Society. 2011 Nov;59:S256-S261. https://doi.org/10.1111/j.1532-5415.20103702.x

52. Population pharmacokinetics. https://www.ema. europa.eu/en/documents/scientific-guideline/ guideline-role-pharmacokinetics-development-medicinal-products-paediatric-population_en.pdf

53. https://www.fda.gov/media/128793/download

54. Cook SF, Bies RR. Disease Progression Modeling: Key Concepts and Recent Developments. Current Pharmacology Reports. 2016 Aug 15;2(5):221-230. https://doi.org/10.1007/s40495-016-0066-x 